\title{
ALELOPATIA ENTRE LEGUMINOSAS ARBÓREAS E FEIJÃO-CAUPI ${ }^{1}$
}

\section{ALLELOPATHY BETWEEN LEGUMINOUS TREE AND COWPEA}

\author{
Ceália Cristine SANTOS ${ }^{2}$ \\ Levy Geralte SILVA ${ }^{3}$ \\ Gilvânia Campos SILVA ${ }^{4}$ \\ Altamiro Souza de Lima FERRAZ JUNIOR ${ }^{5}$
}

\begin{abstract}
RESUMO
O conhecimento das interações entre as leguminosas arbóreas e as culturas anuais é de grande importância para o manejo dos sistemas agroflorestais. Este trabalho avaliou o efeito de extratos aquosos de folhas e raízes de leucena e de guandu sobre sementes de feijão-caupi, bem como a possibilidade das substâncias húmicas reverterem o efeito inibitório desses extratos. Destarte foram conduzidos dois experimentos, no primeiro os tratamentos constaram de extratos de folhas e raízes de guandu e leucena nas dosagens de 0;2; 4; 6; 8 e 10\%; e no segundo constaram de extratos de raízes de guandu e leucena na dosagem de $5 \%$, na presença de substâncias húmicas extraídas do solo nas dosagens de 10, 20, 30 e $40 \%$. Os extratos aquosos de folhas e raízes das duas leguminosas provocaram reduções na germinação de feijão caupi, sendo esta, mais drástica quando se aplicou extratos de raízes. Observou-se um efeito quadrático das doses de extratos aquosos de folhas e de raízes de leucena sobre a redução da germinação de sementes de feijão caupi. A aplicação de extratos de solo contendo substâncias húmicas nas dosagens de 20 e 30\% reverteu o efeito inibidor sobre a germinação do feijão-caupi provocado pelo extrato de raiz de guandu, mas não reverteu a inibição da germinação causada pelo extrato aquoso de raiz de leucena a $5 \%$.
\end{abstract}

Palavras-chave: leucena; guandu; extratos aquosos

\begin{abstract}
The knowledge of the interactions between leguminous tree and crops is of great importance to manage agroforests systems. This work evaluates the effect of leaves and roots aqueous extract of leucaena (Leucaena leucocephala) and pigeon pea(Cajanus cajan) in of cowpea seeds germination and the possibility of the humic substances revert these inhibitory effects. In this sense were carried two experiments, in the first the treatments appear the aqueous extract of leaves and roots of leucaena and pigeon pea at 0,2, 4, 6, 8 and $10 \%(\mathrm{v} / \mathrm{v})$; in the second appear the root aqueous extract of guandu e leucaena in $5 \%(\mathrm{v} / \mathrm{v})$ dosage, with humic substances at $0,10,20,30$ and $40 \%(\mathrm{v} / \mathrm{v})$ concentrations. The aqueous extracts of leguminous leaves and roots caused reductions in the cowpea germination, being this, more dramatic when root extracts were applied. There was a quadratic effect of doses of leucena leaves and root aqueous extracts on the cowpea seeds germination The application of soil extracts containing humic substances in dosages of 20 and $30 \%$ reversed the inhibitory effect on the germination of cowpea caused by the pigeon pea root extracts, but not reversed the allelopathic effects caused by the leucaena roots aqueous extract $(5 \% \mathrm{v} / \mathrm{v})$
\end{abstract}

Key-words: leucaena; guandu; aqueous extracts.

\footnotetext{
1 Trabalho experimental da disciplina "Sinergismo" do Mestrado em Agroecologia da Universidade Estadual do Maranhão.

2 Professora de Geografia, Mestre em Agroecologia da Universidade Federal do Maranhão (UEMA), Av: C Quadra:07, Edifício Constantino, apto. 303, Cond. Novo Tempo 3, Bairro Angelim, São Luís, Maranhão, Brasil. E-mail: cealiasantos@ig.com.br. Autor para correspondência.

${ }^{3}$ Professor de Química do Departamento de Química - CEFET- MA, São Luís, Maranhão, Brasil. E-mail: levygeralte@yahoo.com.br;

${ }^{4}$ Professora de Biologia, Mestre em Agroecologia - Universidade Estadual do Maranhão (UEMA). Jaboticabal, São Paulo, Brasil. E-mail: gilvaniacampos@ig.com.br;

${ }_{5}$ Agrônomo, Professor Adjunto III do Departamento de Química e Biologia da Universidade Estadual de Maranhão (UEMA). São Luís, Maranhão, Brasil. E-mail: altamiro@cecen.uema.br
} 
SANTOS, C.C. et al. Alelopatia entre leguminosas arbóreas...

\section{INTRODUÇÃO}

Alelopatia é a produção de um composto por uma planta que, quando liberado no ambiente, tem um impacto inibidor ou estimulador sobre outros organismos. Os compostos alelopáticos assumem muitas formas, de solúveis em água a voláteis, de simples a complexas, e de vida muito curta a persistentes. Esses compostos liberados para o ambiente por lixiviação, volatilização, exsudação radicular e decomposição de resíduos, entre outros mecanismos possíveis, podem interferir na dinâmica populacional, determinando, em sistemas naturais e cultivados, o padrão e a densidade da vegetação (Souza Filho \& Alves, 2002; Machado, 2007).

Os efeitos que podem ser ocasionados pelos aleloquímicos sobre uma planta são diversos, pois é muito difícil separar os efeitos secundários das causas primárias. Os efeitos visíveis, observados em muitos estudos de alelopatia são, portanto, sinais secundários de mudanças ocorridas ao nível molecular (Medeiros, 1990) e podem apresentar mecanismos de ação diretos, que incluem alterações no crescimento e no metabolismo vegetal. Esses efeitos incluem atraso ou inibição completa da germinação de sementes, crescimento paralisado, injúria no sistema radicular, clorose, murcha e morte das plantas (Correia, 2002).

O sistema de cultivo em aléias é um sistema agroflorestal que combina espécies arbóreas, preferencialmente leguminosas, com culturas de interesse econômico, em uma forma de consórcio onde os ramos das leguminosas são podados e adicionados ao solo para fornecimento de nutrientes e cobertura do solo (Ferraz Jr. et al., 2006). O conhecimento das interações entre as leguminosas arbóreas e as culturas anuais é de grande importância para o manejo dos sistemas agroflorestais, uma vez que as leguminosas estabelecem relações simbióticas com bactérias fixadoras de nitrogênio e servem como cobertura morta e adubo verde.

O guandu (Cajanus cajans, (L.) Druce) e a leucena (Leucaena leucocephala (Lam.) de Wit) são leguminosas muito utilizadas pelos agricultores em sistema agroflorestais simultâneos com culturas anuais (Alves et al., 2004).

Efeitos alelopáticos nesse sistema de cultivo têm sido relatados para as culturas de arroz e milho. Entretanto, alguns autores têm observado que as substâncias húmicas presentes nos solos podem reverter o efeito alelopático de metabólitos secundários como o ácido caféico e ácido ferúlico (Lofredo et al., 2005).

Os efeitos alelopáticos das leguminosas arbóreas sobre a cultura do feijão-caupi foram pouco estudados e precisam ser identificados e compreendidos, dado a importância dessa cultura para a agricultura familiar. Diante do exposto, o objetivo deste estudo foi investigar os possíveis efeitos alelopáticos de extratos de folhas e raízes de guandu e leucena sobre a germinação de sementes e crescimento de plântulas de feijãocaupi e a possibilidade de reversão desses efeitos pela aplicação de substâncias húmicas.

\section{MATERIAL E MÉTODOS}

Foram utilizadas amostras de folhas e raízes frescas das leguminosas leucena (Leucaena leucocephla) e guandu (Cajanus cajans) coletadas no Campo Experimental da Universidade Estadual do Maranhão (UEMA), coordenadas $02^{\circ} 35^{\prime} 30,7^{\prime \prime} \mathrm{S}$ e $44^{\circ} 12^{\prime} 43,3^{\prime \prime} \mathrm{W}$, e postas para secar em estufa elétrica durante $24 \mathrm{~h}$ sob temperatura de $55^{\circ} \mathrm{C}$. As amostras de Leucena foram retiradas de árvores com idade de 11 anos em um sistema agroflorestal. As plantas de guandu foram coletadas de arbustos com um ano após o plantio em sistema de cultivo em aléias. As plantas estavam no estádio de florescimento e frutificação e as coletas foram feitas durante o período chuvoso, no final mês de dezembro de 2007, no período da manhã.

Amostras de folha ou raiz ( $350 \mathrm{~g}$ de cada) foram submetidas à extração em aparelho SOXHLET com $200 \mathrm{~cm}^{3}$ de água destilada, por $4 \mathrm{~h}$. Cada um destes extratos foi diluído à concentração de $0,2,4,6,8$ e $10 \%$.

Para o teste de germinação foi empregado o método do papel Germitest em câmara tipo BOD a $30 \pm 0,2{ }^{\circ} \mathrm{C}$ e fotoperíodo de $12 \mathrm{~h}$. Em cada tratamento avaliado, foram utilizadas quatro repetições de 10 sementes e a avaliação foi realizada sete dias após a instalação do experimento, por meio da contagem de plântulas normais, pelo método da Regra de Análise de Sementes (BRASIL, 1992).

$\mathrm{Na}$ avaliação do comprimento da radícula de plântulas, utilizaram-se os mesmos procedimentos daqueles empregados no teste de germinação, em relação às concentrações. Em três folhas de papel Germitest, umedecidas com os extratos, foram distribuídas 2 fileiras de 10 sementes na parte superior de cada folha, que foram enroladas em forma de cilindro no sentido maior do papel, prendendo as bordas com atilho de borracha. O comprimento da radícula foi medido após a permanência das sementes durante sete dias em câmara tipo BOD a $30 \pm 0,2{ }^{\circ} \mathrm{C}$ de acordo com a Regra de Análise de Sementes. (BRASIL, 1992).

Para avaliar o efeito de extratos de leucena e guandu em conjunto com extratos de substâncias húmicas do solo foram utilizadas amostras de solo até a profundidade de $20 \mathrm{~cm}$ recolhidas em cinco pontos em uma área da UEMA onde se encontra um sistema de cultivo em aléias implantado em 1996. As amostras foram submetidas à análise química apresentando os seguintes resultados: $(\mathrm{pH}$ 4,3; P-disponível (método da resina) $4 \mathrm{mg} \mathrm{dm}^{-3} ; \mathrm{K}$ $0,9 \mathrm{mmol}_{\mathrm{c}} \mathrm{dm}^{-3}$ de TFSA, Ca $11,0 \mathrm{mmol}_{\mathrm{c}} \mathrm{dm}^{-3} ; \mathrm{Mg}$, $2,0 \mathrm{mmol}_{\mathrm{c}} \mathrm{dm}^{-3} ; \mathrm{Al}^{3+} 0,04 \mathrm{mmol}_{\mathrm{c}} \mathrm{dm}^{-3} ; \mathrm{pH}\left(\mathrm{CaCl}_{2}\right) 4,3$ e $\mathrm{C} 12 \mathrm{~g} \mathrm{~kg}^{-3}$. Desse material foi retirada a amostra para análise de substãncias húmicas segundo procedimento recomendado pela IHSS (2009). Vinte gramas de TFSA foram hidratados com $10 \mathrm{~cm}^{3}$ de 
SANTOS, C.C. et al. Alelopatia entre leguminosas arbóreas...

água deionizada, mantidos em $\mathrm{pH}$ ácido com $\mathrm{HCl}$ $0,5 \mathrm{~mol} \mathrm{dm}^{-3}$, situação em que os carbonatos e íons metálicos são solubilizados. $\mathrm{Em}$ seguida a suspensão foi centrifugada a $5000 \mathrm{rpm}$ por $30 \mathrm{~min}$. $\mathrm{O}$ precipitado foi lavado em água deionizada até $\mathrm{pH}$ 7 e a extração das substâncias húmicas foi efetuada com $\mathrm{NaOH} 0,5 \mathrm{~mol} \mathrm{dm}^{-3}$, na proporção 10:1, com 4 h de agitação mecânica, em atmosfera inerte de $\mathrm{N}_{2}$ para evitar oxidação. $\mathrm{O}$ material nãohúmico foi separado por centrifugação a 5000 rpm por $10 \mathrm{~min}$.

Foram obtidos extratos de substâncias húmicas nas concentrações de: 10, 20, 30 e 40\%. Esses extratos foram aplicados isoladamente e em conjunto com uma solução de extrato de raízes de guandu e leucena a $5 \%$ obtidos da mesma forma que no ensaio 1. Utilizou-se como controle a aplicação dos extratos de raízes das leguminosas a $5 \%$.

Os experimentos foram instalados em esquema fatorial, do tipo: 6 (concentrações) $\times 2$ frações das plantas (folhas e raízes) $\times 2$ espécies doadoras (leucena e guandu). inteiramente casualizado, os dados foram submetidos a análise de variância e comparados pelo teste de DMS a $5 \%$ de probabilidade, por meio do software SAEG 8.0. Os dados foram anteriormente avaliados pelo teste de Tukey e observou-se que apenas os dados referentes à leucena foram significativos, sendo que somente estes sofreram analise de regressão.

\section{RESULTADOS E DISCUSSÃO}

A interação entre os fatores leguminosas $x$ partes $\mathrm{x}$ doses quanto a germinação não foi significativa. Portanto foi feita a analise dos fatores isolados $e$ das interações partes $x$ doses $e$ leguminosas $x$ doses. Observou-se que 0 desdobramento da interação evidencia que os extratos de raízes afetaram os índices de germinação de forma mais acentuada. A menor dose dos extratos de raízes provocou redução na germinação equivalente aquela causada pela aplicação de extratos de folhas na maior dose (Tabela 1).

TABELA 1 - Médias da germinação (\%) de sementes de feijão-caupi sob efeito do extrato das folhas e raízes de leucena e guandu.

\begin{tabular}{ccccc}
\hline Extratos (\%) & \multicolumn{2}{c}{ Folha } & \multicolumn{2}{c}{ Raiz } \\
\cline { 2 - 5 } & Leucena & Guandu & Leucena & Guandu \\
\hline 0 & $82,5 \mathrm{a}$ & $82,5 \mathrm{a}$ & $82,5 \mathrm{a}$ & $82,5 \mathrm{a}$ \\
2 & $82,5 \mathrm{a}$ & $77,5 \mathrm{ab}$ & $47,5 \mathrm{~b}$ & $52,5 \mathrm{~b}$ \\
4 & $75,0 \mathrm{~b}$ & $60,0 \mathrm{~cd}$ & $55,0 \mathrm{bc}$ & $47,5 \mathrm{~b}$ \\
6 & $57,5 \mathrm{~b}$ & $70,0 \mathrm{bc}$ & $50,0 \mathrm{bc}$ & $40,0 \mathrm{~b}$ \\
8 & $60,0 \mathrm{~b}$ & $50,0 \mathrm{~d}$ & $42,5 \mathrm{bc}$ & $42,5 \mathrm{~b}$ \\
\hline
\end{tabular}

Médias seguidas de letras iguais na coluna não diferem entre si pelo teste DMS ao nível de 5\%; CV=20\%

O desdobramento da interação mostra diferenças entre as doses dos extratos aquosos de folhas da leguminosa Leucaena leucocephala (Lam.) de Wit, sobre a germinação do feijão caupi com efeito quadrático $\left(R^{2}=0,65^{\star *}\right)$ (Figura 1). As doses superiores a $6 \%$ de extrato de folhas provocaram reduções significativas na germinação do feijão-caupi, com efeito mais expressivo sobre a inibição da germinação da dose de 10\% (Tabela 1).

$O$ extrato de raiz de leucena aplicado em diferentes concentrações afetou a germinação de feijão caupi com efeito quadrático $\left(R^{2}=0,46^{*}\right)$ (Figura 2). A germinação das sementes variou de 42,5 a $55,5 \%$, com todas as doses diferentes da testemunha, porém não houve diferença entre as doses.

Observou-se uma redução na germinação das sementes de feijão caupi em função da aplicação de extrato aquosos de folhas de guandu. Nas concentrações de $8 \%$ do extrato houve somente $50 \%$ de germinação. Nas concentrações de 4 e $10 \%$ foram observados valores de $60 \%$ de germinação, as concentrações de 2 e $6 \%$ mostraram germinação de 77,5 e $70 \%$ respectivamente, sendo os valores que mais se aproximaram da testemunha. No que diz respeito aos extratos de raiz de guandu, as concentrações com 4,6 e $8 \%$ do extrato apresentaram os menores índices de germinação (42 a 47,5\%), mostrando maior potencial de inibição alelopática, não diferindo entre si, mas diferindo da testemunha (Tabela 1).

Pires et al. (2001a) realizaram estudos com leucena e observaram redução na germinação do picão-preto pelo extrato aquoso a $5 \%$. Prates et al. (2000); Pires et al. (2001b) não encontraram diferenças quanto a produção e a germinação de sementes de milho, sob efeito de extratos de folhas de leucena, em condições de campo, mas observaram significativa diminuição do comprimento da raiz seminal e biomassa seca das plântulas de milho, sob estes extratos. 
SANTOS, C.C. et al. Alelopatia entre leguminosas arbóreas...

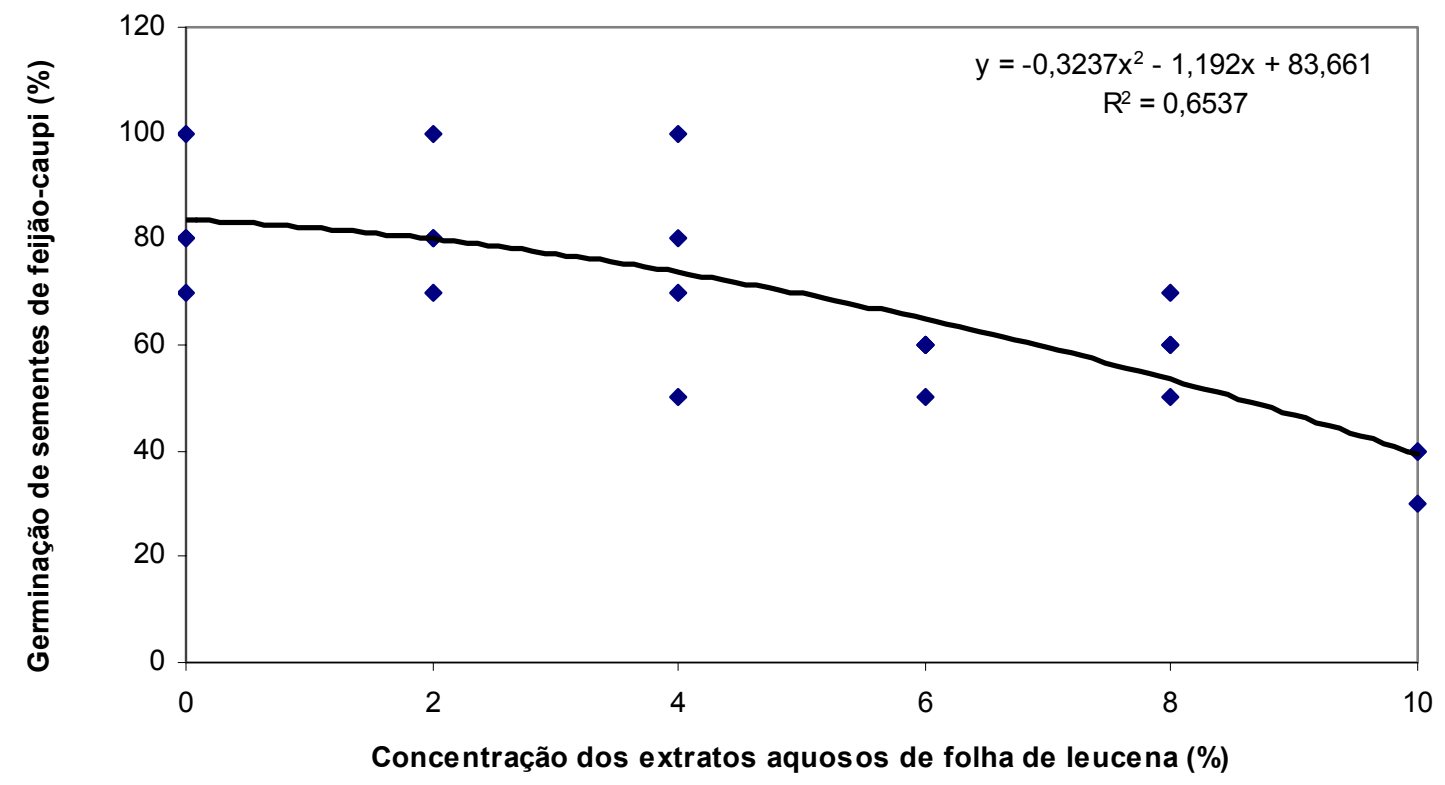

FIGURA 1 - Efeito de extratos aquosos de folha de leucena sobre a germinação do feijão-caupi (\%)

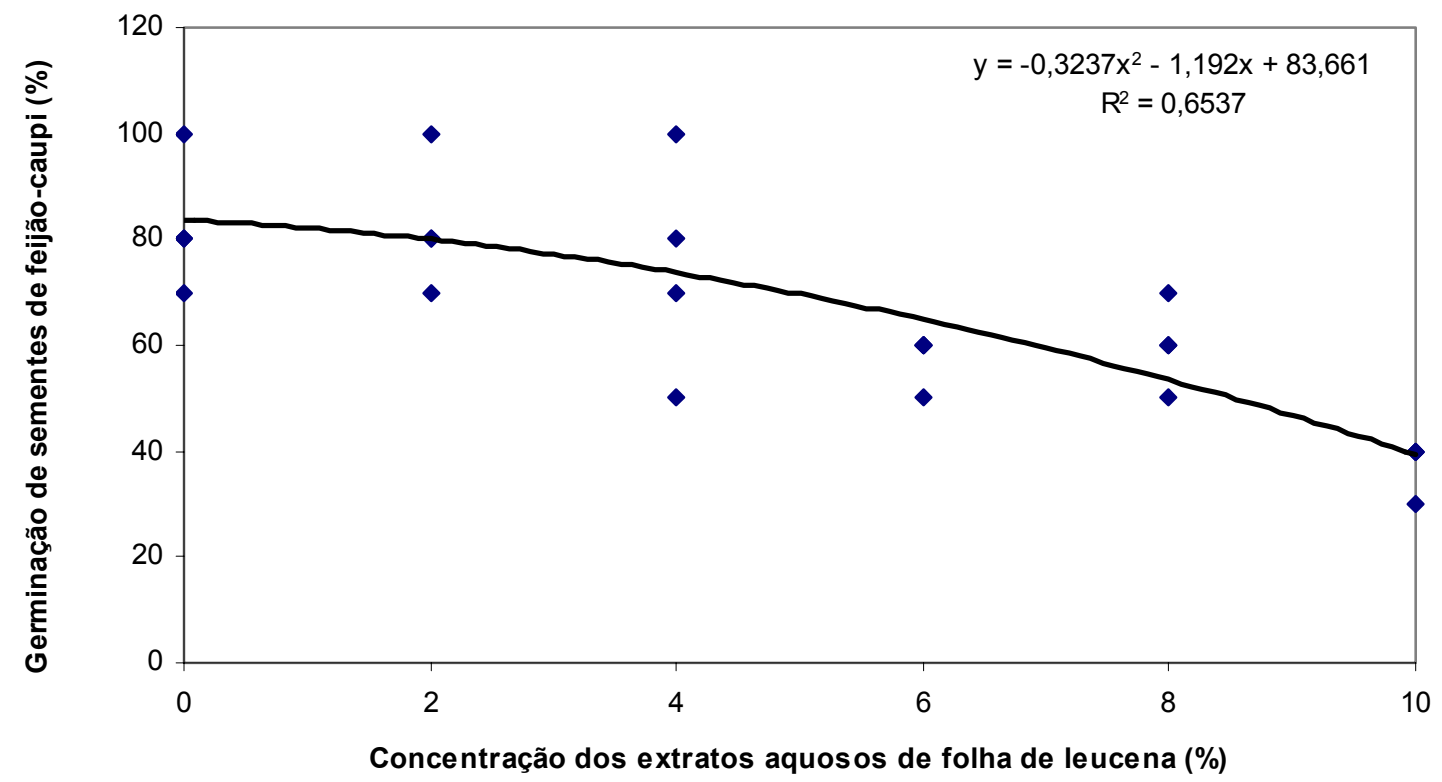

FIGURA 2 - Efeito de extratos aquosos de raízes de leucena sobre a germinação do feijão-caupi (\%)

Em relação ao feijão guandu, Teixeira et al. (2004) avaliaram seus efeitos alelopáticos nas sementes de alface e observaram que houve uma tendência de redução de $67,3 \%$ na germinação. Em condições de campo, estes autores observaram, também na cultura de feijão, menores estandes em palhadas provenientes do consórcio de milheto (Pennisetum typhoides) com feijão-de-porco e guandu anão (Cajanus cajans), quando comparados ao estande alcançado sob palhada exclusiva do milheto, atribuindo o fato a possíveis efeitos alelopáticos das leguminosas.

Os extratos com raiz de leucena e substâncias húmicas não apresentaram diferenças na germinação em nenhuma das concentrações estudadas em relação à testemunha. Os extratos com raiz de guandu e substâncias húmicas nas concentrações de 20 e $30 \%$ mostraram melhor germinação das sementes de feijão-caupi, limitando o efeito alelopático da leguminosa, e ultrapassando o índice de germinação da testemunha (Tabela 2). Esse efeito pode ser atribuído à adsorção dos 
SANTOS, C.C. et al. Alelopatia entre leguminosas arbóreas...

aleloquímicos pelos grupos carboxílicos das substâncias húmicas de cadeias menores que apresentam maior atividade. (Lofredo et al. (2005). Esses autores observaram que substâncias húmicas exerceram um efeito modelador sobre o efeito alelopático de ácido ferúlico, ácido cafeico e ácido salićlico, três compostos inibidores de germinação e do crescimento de sementes e plântulas de alface e tomate.

TABELA 2 - Germinação (\%) de feijão-caupi sob efeito de substâncias húmicas do solo e extrato de raiz de leucena e guandu a $5 \%$.

\begin{tabular}{ccc}
\hline Extratos (\%) & \multicolumn{2}{c}{ Raiz } \\
\cline { 2 - 3 } & Leucena & Guandu \\
\hline Testemunha & $65,0 \mathrm{a}$ & $62,5 \mathrm{~b}$ \\
10 & $72,5 \mathrm{a}$ & $60,0 \mathrm{~b}$ \\
20 & $67,5 \mathrm{a}$ & $90,0 \mathrm{a}$ \\
30 & $65,0 \mathrm{a}$ & $87,5 \mathrm{a}$ \\
40 & $45,0 \mathrm{a}$ & $52,5 \mathrm{~b}$
\end{tabular}

Médias seguidas de letras iguais na coluna não diferem entre si pelo teste DMS ao nível de; CV= 19,1\%

Os efeitos alelopáticos podem ser observados tanto sobre a germinação quanto sobre o crescimento de plântulas. Segundo Jacobi \& Ferreira (1991) o efeito é mais intenso sobre o crescimento do que sobre a germinação. Em contraposição à afirmativa acima, observou-se no presente trabalho que os extratos aquosos de folhas e raízes de leucena e guandu não afetaram o crescimento das plântulas de feijão-caupi (Tabela 3). Resultados semelhantes foram obtidos por Prates et al. (2000), que não observaram influência no crescimento das raízes de milho submetidos à aplicação de extratos aquosos de folhas de leucena.

TABELA 3 - Média do comprimento $(\mathrm{cm})$ de plântulas de feijão-caupi sob efeito do extrato de folhas e raízes de leucena e guandu.

\begin{tabular}{ccccc}
\hline Extratos (\%) & \multicolumn{2}{c}{ Folha } & \multicolumn{2}{c}{ Raiz } \\
\cline { 2 - 5 } & Leucena & Guandu & $33,1 \mathrm{a}$ & $33,1 \mathrm{a}$ \\
\hline 0 & $33,1 \mathrm{a}$ & $33,1 \mathrm{a}$ & $30,3 \mathrm{bc}$ & $31,0 \mathrm{c}$ \\
2 & $29,1 \mathrm{a}$ & $32,6 \mathrm{a}$ & $33,0 \mathrm{a}$ & $32,8 \mathrm{ab}$ \\
4 & $28,1 \mathrm{a}$ & $30,7 \mathrm{a}$ & $28,5 \mathrm{c}$ & $31,0 \mathrm{c}$ \\
6 & $31,2 \mathrm{a}$ & $33,2 \mathrm{a}$ & $33,8 \mathrm{a}$ & $30,2 \mathrm{c}$ \\
10 & $30,5 \mathrm{a}$ & $33,0 \mathrm{a}$ & $32,5 \mathrm{ab}$ & $34,1 \mathrm{a}$
\end{tabular}

Médias seguida de letras iguais na coluna não diferem entre si pelo teste DMS ao nível de $5 \%$ CV= $17,5 \%$

\section{CONCLUSÕES}

Extratos aquosos de raízes e folhas das leguminosas arbóreas utilizadas em Sistemas Agroflorestais exerceram efeitos deletérios sobre a germinação das sementes de feijão caupi, com maior intensidade para os extratos de guandu. As substâncias húmicas reduziram o efeito inibidor do extrato aquoso de raiz de guandu sobre a germinação de sementes de feijão-caupi, o que pode ser um mecanismo importante para o bom desempenho do feijão caupi em sistemas agroflorestais com essa leguminosa.

\section{REFERÊNCIAS}

1. ALVES, S. M. C. et al. Balanço do nitrogênio e fósforo em solo com cultivo orgânico de hortaliças após a incorporação de biomassa de guandu. Pesquisa Agropecuária Brasileira, v. 39, n. 11, p. 1111-1117, 2004.

2. BRASIL. Ministério da Agricultura. Regra de Análise de Sementes. Brasília: CLAV, 1992. 365 p. 
SANTOS, C.C. et al. Alelopatia entre leguminosas arbóreas...

3. CORREIA, N. M. Palhadas de sorgo associadas ao herbicida imazamox no controle de plantas daninhas e no desenvolvimento da cultura da soja em sucessão. 2002. 59 f. Dissertação (Mestrado em Fitotecnia) - Universidade Federal de Lavras, Lavras, 2002.

4. FERRAZ JUNIOR, A. S. L. et al. Fitomassa, distribuição de raízes e aporte de nitrogênio e fósforo por leguminosas cultivadas em aléias em solo de baixa fertilidade. Floresta e ambiente, v. 13, n. 1, p. 61-68, 2006.

5. International Humic Substance Society (IHSS). Isolamento da IHSS solos ácidos húmicos e fúlvicos. Disponível em: < http://ihss.gatech.edu/ihss2/isolation.html>. Acesso em: 30 mai. 2009.

6. JACOBI, U. S.; FERREIRA, A. G. Efeitos alelopáticos de Mimosa bimocronata sobre espécies cultivadas. Pesquisa Agropecuária Brasileira, v. 26, n. 7, p. 935-943, 1991.

7. LOFFREDO, E.; MONACI, L.; SENESI, N. Humic substances can modulate the allelopathic potential of caffeic, ferulic, and salicylic acids for seedlings of lettuce(Lactuca sativa L.) and tomato (Lycopersicon esculentum Mill.). Journal of Agricultural and Food Chemistry, v. 53, n. 24, p. 9424-9430, 2005

8. MACHADO, S. Allelopathic Potential of Various Plant Species on Downy Brome. Agronomy Journal, v. 99, n. 1, p. 127$132,2007$.

9. MEDEIROS, A. R. M. Alelopatia: importância e suas aplicações. Hortisul, v. 1, n. 3, p. 27-33, 1990.

10.PIRES, N. M. et al. Atividade alelopática da leucena sobre espécies de plantas daninhas. Scientia Agrícola, v. 58 , n. 1, p. 61-65, 2001a.

11.PIRES, N. M. et al. Efeito do extrato aquoso de leucena sobre o desenvolvimento, índice mitótico e atividade da peroxidase em plântulas de milho. Revista Brasileira de Fisiologia Vegetal, v. 13, n. 1, p. 55-65, 2001 b.

12.PRATES, H. T. et al. Efeito do extrato aquoso de leucena na germinação e no desenvolvimento do milho. Pesquisa Agropecuária Brasileira, v. 35, n. 5, p. 909-914, 2000.

13.SOUZA FILHO, A. P. S.; ALVES, S. M. (Ed.). Alelopatia: princípios básicos e aspectos gerais. Belém: EMBRAPA, 2002. $260 \mathrm{p}$.

14.TEIXEIRA, C. M.; ARAÚJO, J. B. S.; CARVALHO, G. J. Potencial alelopático de plantas de cobertura no controle de picão-preto (Bidens pilosa L. Revista Ciência e Agrotecnologia, v. 28, n. 3, p. 691-695, 2004.

Recebido em 16/01/2009

Aceito em 08/12/2009 